\title{
Novel Approach for the Synthesis of Nanocrystalline Anatase Titania and Their Photovoltaic Application
}

\author{
Pavuluri Srinivasu, ${ }^{1}$ Surya Prakash Singh, ${ }^{2}$ Ashraful Islam, ${ }^{2,3}$ and Liyuan Han ${ }^{2}$ \\ ${ }^{1}$ International Center for Young Scientists, International Center for Materials Nanoarchitectonics, \\ National Institute for Materials Science, 1-1 Namiki, Tsukuba, Ibaraki 305-0044, Japan \\ ${ }^{2}$ Photovoltaics Materials Unit, National Institute for Materials Science, 1-2-1 Sengen, Tsukuba, Ibaraki 305-0047, Japan \\ ${ }^{3}$ Center of Excellence for Research in Engineering Materials (CEREM), College of Engineering, King Saud University, \\ Riyadh 11421, Saudi Arabia
}

Correspondence should be addressed to Pavuluri Srinivasu, pavuluri.srini@gmail.com

Received 30 April 2011; Accepted 26 May 2011

Academic Editor: Idriss M. Bedja

Copyright ( 2011 Pavuluri Srinivasu et al. This is an open access article distributed under the Creative Commons Attribution License, which permits unrestricted use, distribution, and reproduction in any medium, provided the original work is properly cited.

\begin{abstract}
High surface area titania with crystalline anatase walls has been synthesized using ordered large mesoporous carbon as a template. The pore structure of mesoporous carbon is infiltrated with titanium tetraisopropoxide solution at room temperature and the mixture is subjected to heat treatment at $550^{\circ} \mathrm{C}$ in presence of air to complete removal of the template. The prepared crystalline anatase frameworks are characterized by XRD, $\mathrm{N}_{2}$ adsorption and HR-TEM. The nitrogen adsorption-desorption analysis of the prepared anatase titania particles exhibits BET specific surface area of $28 \mathrm{~m}^{2} / \mathrm{g}$. The dye-sensitized solar cells performance of this anatase titania material has been tested and energy conversion efficiency of $3.0 \%$ is achieved under AM 1.5 sunlight. This work reports a new approach for fabrication of nanocrystalline anatase titania by simple hard templating technique for the first time and their applications for dye-sensitized solar cell.
\end{abstract}

\section{Introduction}

The use of solar cells for energy production by converting sunlight directly into electricity is an avenue to address global energy demand and clean alternative power generation devices. Most commonly used solar cell technologies include crystalline silicon, thin film concentrators, and thermophotovoltaic solar cells. Silicon-based solar cells are largescale, single-junction devices, and a very high percentage of photovoltaic production comes from these solar cells $[1,2]$. The thin-film solar cells are aimed to decrease the amount of expensive material used in production process without sacrificing efficiency. The materials used in thinfilm solar cells are amorphous silicon, $\mathrm{CuIn}(\mathrm{Ga}) \mathrm{Se}_{2}$ (CIGS) and $\mathrm{CdTe} / \mathrm{CdS}$, which are deposited on thin low-cost glass or copper foil substrate [3,4]. An alternative approach using multijunction solar cells of dye-sensitized solar cells (DSCs) and organic solar cells (OSCs) are also developed to reduce the cost furthermore $[5,6]$. In recent years, DSCs have attracted a great deal of attention due to their simple fabrication and low production cost. DSCs are composed of porous nanostructured oxide film with adsorbed dye molecules as a dye-sensitized anode, an electrolyte containing iodide/triiodide redox couple, and a platinized fluorinedoped tin oxide (FTO) glass as counter electrode [7-9]. In DSCs high internal surface area and wide band gap semiconductor material with adsorbed dye as a photoanode plays an important role. The choice of semiconductor depends on its conduction band, density state that allows efficient electronic coupling with the dye energy level to facilitate charge separation and minimize recombination. Additionally, the semiconductor material must have high internal surface area to maximize light absorption by the dye monolayer with good electrical conductivity to the substrate. Among many other metal oxide semiconductors, nanocrystalline titania is of great scientific and technological interest due to its excellent performance in solar cells [10, 11], photocatalysis [12], photochromism [13], sensors [14], 
and so forth. Further, anatase titania nanocrystals are used as best recipient of injected electrons from optically excited dye and provides the conductive pathway to the circuit. However, the preparation of crystalline titania by hard templating technique involves silica, which requires strong acid or base for complete removal of template $[15,16]$.

Recently, P. Srinivasu et al.'s research on dye-sensitized solar cells has clearly demonstrated that large mesoporous carbon thin film can act as metal-free counter electrode with very high energy conversion efficiency [17]. The work in Srinivasu et al. concentrated on the use of large porous two-dimensional hexagonal carbon, where properties of the carbon material depends on its ordered two-dimensional pore structure and surface area.

The recent research on templated synthesis of mesoporous carbon using three-dimensional mesoporous silica (KIT-6) has attracted a lot of attension for applications in catalysis and adsorption studies [18]. However, threedimensional mesoporous carbon prepared from KIT-6, has not been used as a hard template for the fabrication of anatase titania in the open literature. Here we report nanocrystalline anatase titania synthesized using threedimensional mesoporous carbon as a hard template through combustion technique and characterize the prepared material by powder X-ray diffraction, nitrogen adsorption, and electron microscopy techniques. Dye-sensitized solar cell device is constructed with nanocrystalline anatase titania thin film and studied the performance of the material.

\section{Experimental}

2.1. Preparation of Mesoporous Carbon and Anatase Crystalline Titania. Ordered mesoporous carbon material refered to as CTS-6 (carbon from three-dimensional silica-6) is synthesized by pyrolysis of sucrose inside the large-pore mesoporous silica (KIT-6) synthesized at $100^{\circ} \mathrm{C}$. In a typical synthesis of mesoporous carbon, $1 \mathrm{~g}$ of KIT- 6 is added to a solution obtained by dissolving $0.75 \mathrm{~g}$ of sucrose and $5.0 \mathrm{~g}$ of water, and keeping the mixture in an oven for $6 \mathrm{~h}$ at $100^{\circ} \mathrm{C}$. Subsequently, the oven temperature was raised to $160^{\circ} \mathrm{C}$ for another $6 \mathrm{~h}$. In order to obtain fully polymerized and carbonized sucrose inside the pores of silica template, $0.5 \mathrm{~g}$ of sucrose, $0.06 \mathrm{~g}$ of $\mathrm{H}_{2} \mathrm{SO}_{4}$, and $5.0 \mathrm{~g}$ of water are again added to the pretreated sample and the mixture is again subjected to the thermal treatment described above. Carbonization is performed at $900^{\circ} \mathrm{C}$ for $5 \mathrm{~h}$ under $\mathrm{N}_{2}$ atmosphere. The resulting carbon/silica composite is treated with $\mathrm{HF}$ acid ( $5 \mathrm{wt} \%$ ) at room temperature to selectively removal of silica. Anatase crystalline titania is prepared by adding $20 \mathrm{~mL}$ of titanium tetraisopropoxide $\left(1.5 \mathrm{~mol} \mathrm{~L}^{-1}\right)$ solution and stirring at room temperature for $6 \mathrm{~h}$. The impregnated carbon material is dried at room temperature and heated under air at $550^{\circ} \mathrm{C}$ for $4 \mathrm{~h}$. The final anatase titania material is used to prepare a film on FTO glass using doctor-blade technique [16] and [17], which is ultrasonically cleaned in ethanol prior to use.

Powder X-ray diffraction patterns were obtained through a Rigaku diffractometer using $\operatorname{CuK} \alpha(\lambda=0.154 \mathrm{~nm})$ radiation. $\mathrm{N}_{2}$ adsorption-desorption isotherms are measured at
77 K on a Quantachrome Autosorb 1 volumetric adsorption analyzer. Before the adsorption measurements, all samples are out gassed at $250^{\circ} \mathrm{C}$ in the port of the adsorption analyzer. The position of the maximum on pore size distribution is referred to as the pore diameter, which was calculated from adsorption branches by Barret-Joyner-Halenda (BJH) method. The HRTEM images are obtained with JEOL JEM$2100 \mathrm{~F}$. Hitachi S-4800 HR-FESEM is used to observe the morphology of the material.

\subsection{Fabrication of Dye-Sensitized Solar Cell}

2.2.1. Preparation of Titania Electrode. The dye solutions ( $0.3 \mathrm{mM}$ solution of N719 dye) were prepared in $1: 1$ acetonitrile and tert-butyl alcohol solvents. Deoxycholic acid as a coadsorbent was added to the dye solution at a concentration of $20 \mathrm{mM}$. The electrodes were immersed in the dye solutions and then kept at $25^{\circ} \mathrm{C}$ for $24 \mathrm{~h}$ to adsorb the dye onto the $\mathrm{TiO}_{2}$.

2.2.2. Preparation of Dye-Sensitized Solar Cell. Photovoltaic measurements were performed in a two-electrode sandwich cell configuration. The dye-deposited $\mathrm{TiO}_{2}$ film and a platinum-coated conducting glass were used as the working electrode and the counter electrode, respectively. The two electrodes were separated by a surlyn spacer ( $40 \mu \mathrm{m}$ thick) and sealed up by heating the polymer frame. The electrolyte was composed of $0.6 \mathrm{M}$ dimethylpropyl-imidazolium iodide (DMPII), 0.05 $\mathrm{M} \mathrm{I}_{2}$, TBP 0.5 M, and 0.1 M LiI in acetonitrile (AN).

\section{Results and Discussion}

Powder X-ray diffraction pattern is measured for titaniumtetraisopropoxide impregnated mesoporous carbon sample after removal of carbon template through combustion process in presence of air. Figure 1 (a) shows powder XRD patterns of resulting material in the range of $2 \theta=10-80^{\circ}$. The well-defined sharp Bragg peaks indicate highly crystalline nature of the material. The Bragg diffraction peaks indexed as (101), (112), (200), (105), (211), (204), (116), (220), and (215) are correspond to anatase phase $\mathrm{TiO}_{2}$ with tetragonal arrangement. However, mesoporous ordered structure could not be retained after complete removal of the template due to incomplete filling of pore structure with titanium precursors. The nitrogen adsorption-desorption isotherm for crystalline anatase titanium oxide is shown in Figure 1(b). The BET specific surface area obtained for prepared anatase $\mathrm{TiO}_{2}$ is $28 \mathrm{~m}^{2} / \mathrm{g}$, which is remarkable.

Figure 2(a) shows high resolution TEM images of the nanocrystalline titania particles with particle size in the range of $5-6 \mathrm{~nm}$. It is very interesting to note the particle size is smaller than commercially available $\mathrm{TiO}_{2}$ (P-25 Degussa, average particle size $25-30 \mathrm{~nm}$ ). The circled areas in Figure 2(b), which are in regular pattern, show that all particles are in anatase form. Corresponding SAED pattern (Figure 2(c)) indicates polycrystalline nature of the material. The interplanar spacing (d) obtained from computed SAED 


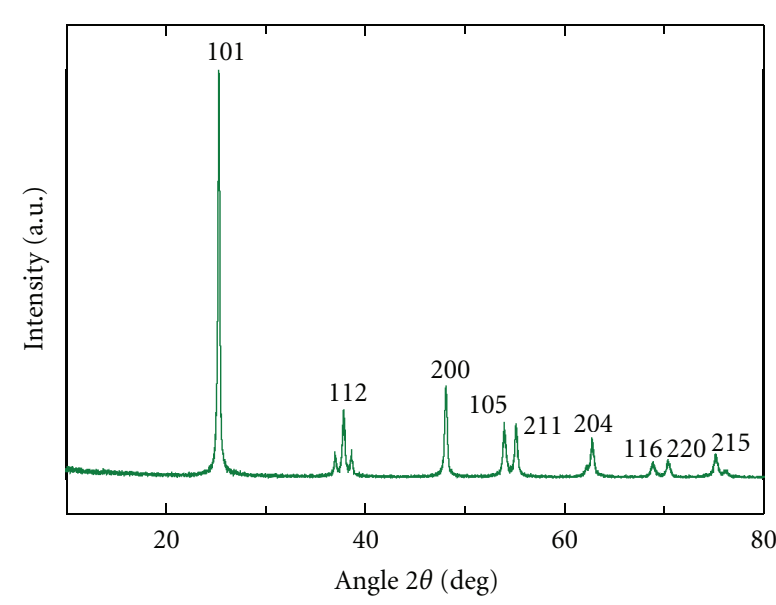

(a)

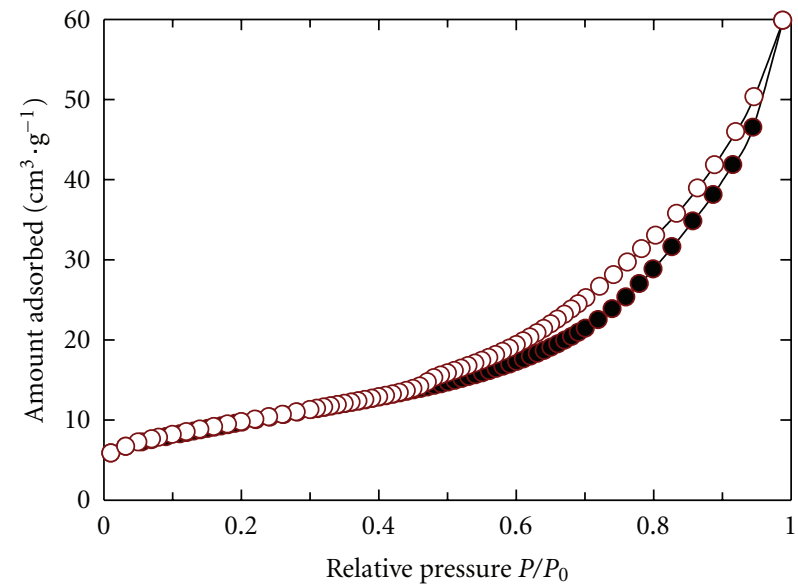

(b)

FIgure 1: (a) Powder XRD pattern of anatase $\mathrm{TiO}_{2}$ and (b) nitrogen adsorption-desorption isotherm of anatase $\mathrm{TiO}_{2}(\bullet-$ adsorption, $\circ$ desorption).

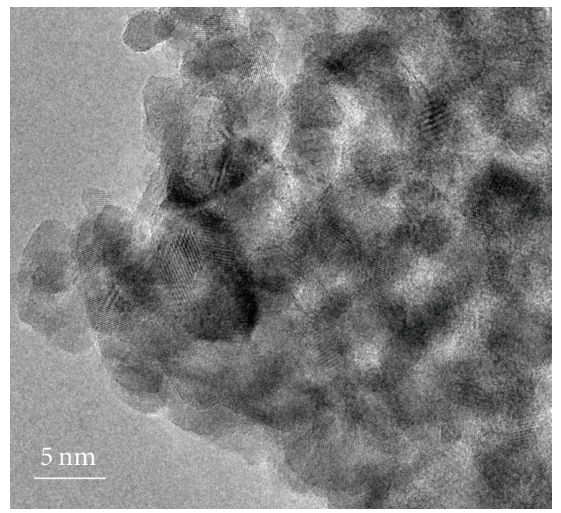

(a)

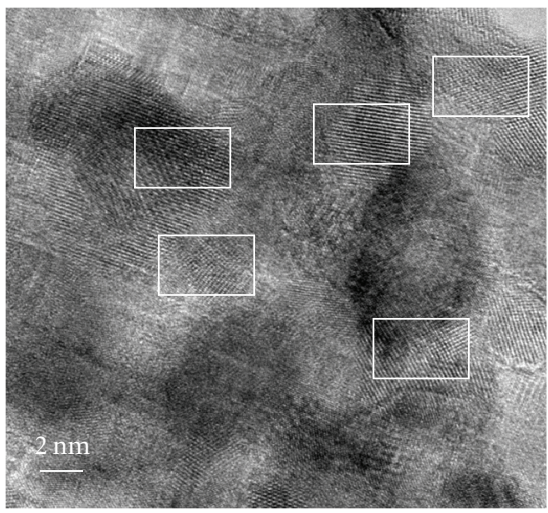

(b)

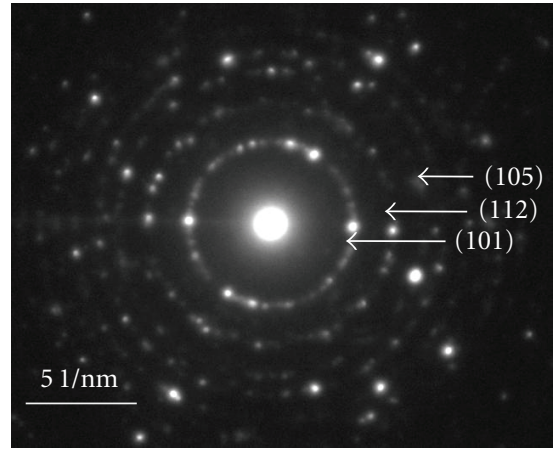

(c)

Figure 2: (a, b) High-resolution transmission electron microscopy images and (c) selected area electron diffraction (SAED) pattern of nanocrystalline titania.

pattern is well matched with data obtained from XRD. The results obtained from XRD and HRTEM clearly conclude that the synthesized $\mathrm{TiO}_{2}$ particles are in anatase crystalline form. This confirms that material of very small anatase $\mathrm{TiO}_{2}$ particles can be prepared using mesoporous carbon template approach. Figure 3(a) shows current-voltage characteristics obtained for the cell with anatase $\mathrm{TiO}_{2}$ thin film.

Monochromatic incident photon-to-current conversion efficiency (IPCE) for the solar cell, plotted as a function of excitation wavelength, was recorded on a CEP-2000 system (Bunkoh-Keiki Co. Ltd.). IPCE at each incident wavelength was calculated from equation given below, where $I_{\mathrm{sc}}$ is the photocurrent density at short circuit in $\mathrm{mA} \mathrm{cm}^{-2}$ under monochromatic irradiation, $q$ is the elementary charge, $\lambda$ is the wavelength of incident radiation in $\mathrm{nm}$, and $P_{0}$ is the incident radiative flux in $\mathrm{Wm}^{-2}$

$$
\operatorname{IPCE}(\lambda)=1240\left(\frac{I_{\mathrm{sc}}}{q \lambda P_{0}}\right) .
$$

The photocurrent density-voltage curves and incident photon-to-current efficiency (IPCE) spectra of the cells based on N719 dye under the illumination of air mass (AM) 1.5 sunlight $\left(100 \mathrm{~mW} / \mathrm{cm}^{2}\right.$, WXS-155S-10: Wacom Denso Co., Japan).

The titania thin film is coated on FTO conductive glass twice using anatase $\mathrm{TiO}_{2}$ gel. The prepared titania thin film is dipped into N719 dye, and then photocurrent voltage characteristics are measured by irradiating with simulated AM1.5 $100 \mathrm{~mW} / \mathrm{cm}^{2}$ solar light. The short-circuit current $\left(J_{\text {sc }}\right)$, the open-circuit voltage $\left(V_{\mathrm{oc}}\right)$, and the fill factor $(\mathrm{FF})$ values obtained for nanocrystalline $\mathrm{TiO}_{2}$ are 6.19, 0.819, and $0.64 \%$, respectively. It is interesting to observe that high overall conversion efficiency $(\eta)$ is $3.24 \%$ this is due to anatase titania high crystallinity and high specific surface area. The IPCE result of DSCs is shown in Figure 3(b). The anatase nanocrystalline titania thin film showing broad IPCE spectra between 500 and $600 \mathrm{~nm}$ indicates higher N719 dye absorption capacity. It can also be seen that the maximum IPCE value at $530 \mathrm{~nm}$ of the cell made from anatase titania 


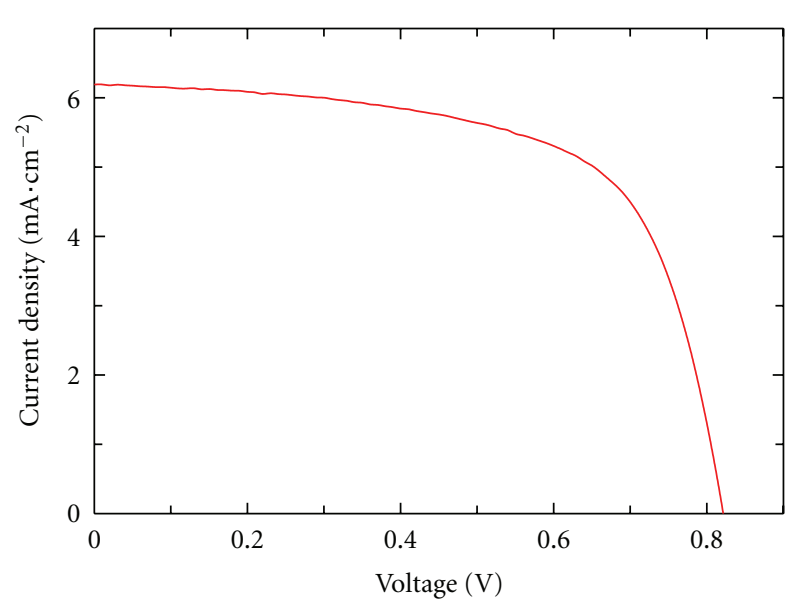

(a)

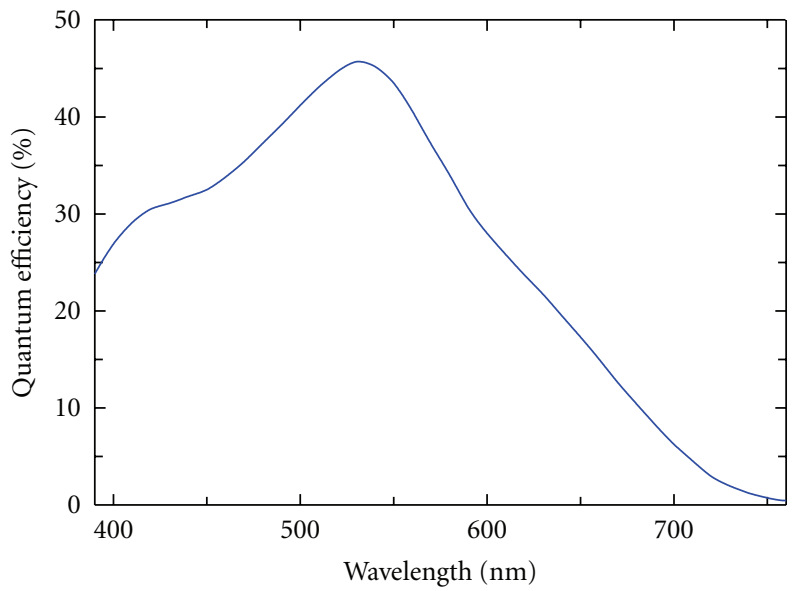

(b)

Figure 3: (a) Photocurrent-voltage ( $I-V)$ characteristics and (b) incident photon-to-current conversion efficiency (IPCE) spectra of dyesensitized solar cells of anatase $\mathrm{TiO}_{2}$ particles.

thin films is approximately $46 \%$, which is interesting. These results clearly show dye-sensitized solar cells fabricated with the prepared anatase titania thin film show good solar-toelectricity conversion.

\section{Conclusions}

A nanocrystalline anatase titania with average particle size of $5 \mathrm{~nm}$ was successfully synthesized by mesoporous carbon hard template. The synthesized $\mathrm{TiO}_{2}$ particles were fully anatase crystalline form, which was confirmed by various characterization techniques. The BET-specific surface obtained for this material was $28 \mathrm{~m}^{2} / \mathrm{g}$. The novel approach used for the synthesis of nanocrystalline anatase titania using mesoporous carbon as a hard template by combustion process may also be applied to synthesize other metal oxides, such as $\mathrm{Cu}, \mathrm{Sn}, \mathrm{Zr}$, and so forth. Light-to-electricity conversion yield of $3.24 \%$ was achieved by applying the nanocrystalline anatase titania thin film of dye-sensitized solar cells.

\section{Acknowledgments}

P. Srinivasu thanks the International Center for Young Scientists (ICYS) and International Center for Materials Nanoarchitectonics (MANA) at the National Institute for Materials Science, Tsukuba, Japan for financial support.

\section{References}

[1] D. E. Carlson and C. R. Wronski, "Amorphous silicon solar cell," Applied Physics Letters, vol. 28, no. 11, pp. 671-673, 1976.

[2] G. Yue, B. Yan, G. Ganguly, J. Yang, S. Guha, and C. Teplin, "Material structure and metastability of hydrogenated nanocrystalline silicon solar cells," Applied Physics Letters, vol. 88, no. 26, pp. 263507-263507, 2006.

[3] S. Guha and J. Yang, "Science and technology of amorphous silicon alloy photovoltaics," IEEE Transactions on Electron Devices, vol. 46, no. 10, pp. 2080-2085, 1999.

[4] J. Yang, A. Banerjee, and S. Guha, "Triple-junction amorphous silicon alloy solar cell with $14.6 \%$ initial and $13.0 \%$ stable conversion efficiencies," Applied Physics Letters, vol. 70, no. 22, pp. 2975-2977, 1997.

[5] B. O'Regan and M. Grätzel, "A low-cost, high-efficiency solar cell based on dye-sensitized colloidal $\mathrm{TiO}_{2}$ films," Nature, vol. 353, no. 6346, pp. 737-740, 1991.

[6] S. M. Zakeeruddin, M. K. Nazeeruddin, and R. H. Baker, "Design, synthesis and application of amphilic ruthenium polypyridyl photosensitizers in solar cells based on nanocrystalline $\mathrm{TiO}_{2}$ films," Langmuir, vol. 18, pp. 952-954, 2002.

[7] M. S. Dresselhaus and I. L. Thomas, "Alternative energy technologies," Nature, vol. 414, no. 6861, pp. 332-337, 2001.

[8] M. Grätzel, "Photoelectrochemical cells," Nature, vol. 414, no. 6861, pp. 338-344, 2001.

[9] J. Bisquert, D. Cahen, G. Hodes, S. Rühle, and A. Zaban, "Physical chemical principles of photovoltaic conversion with nanoparticulate, mesoporous dye-sensitized solar cells," Journal of Physical Chemistry B, vol. 108, no. 24, pp. 8106-8118, 2004.

[10] C. J. Barbé, F. Arendse, P. Comte et al., "Nanocrystalline titanium oxide electrodes for photovoltaic applications," Journal of the American Ceramic Society, vol. 80, no. 12, pp. 3157-3171, 1997.

[11] B. Oregan, D. T. Schwartz, S. M. Zakeeruddin, and M. Gratzel, "Microfabrication of ceramics by filling of photoresist molds," Advanced Materials, vol. 12, pp. 1263-1267, 2000.

[12] K. Vinodgopal, D. E. Wynkoop, and P. V. Kamat, "Environment photochemistry on semiconductor surfaces: photosensitized degradation of a textile azo dye, acid organge 7, on $\mathrm{TiO}_{2}$ particles using visible light," Environmental Science Technology, vol. 30, pp. 1660-1666, 1996.

[13] K. Naoi, Y. Ohko, and T. Tatsuma, " $\mathrm{TiO}_{2}$ films loaded with silver nanoparticles: control of multicolor photochromic behavior," Journal of the American Chemical Society, vol. 126, no. 11, pp. 3664-3668, 2004.

[14] M. Tiemann, "Porous metal oxides as gas sensors," Chemistry-A European Journal, vol. 13, no. 30, pp. 83768388, 2007.

[15] B. Tian, X. Liu, H. Yang et al., "General synthesis of ordered crystallized metal oxide nanoarrays replicated by microwavedigested mesoporous silica," Advanced Materials, vol. 15, no. 16, pp. 1370-1373, 2003. 
[16] H. Yang, Q. Shi, B. Tian et al., "One-step nanocasting synthesis of highly ordered single crystalline indium oxide nanowire arrays from mesostructured frameworks," Journal of the American Chemical Society, vol. 125, no. 16, pp. 4724-4725, 2003.

[17] P. Srinivasu, S. P. Singh, A. Islam, and L. Han, "MetalFree counter electrode for efficient dye-sensitized solar cells through high surface area and large porous carbon," International Journal of Photoenergy, vol. 2011, Article ID 617439, 4 pages, 2011.

[18] K. P. Gierszal, T.-W. Kim, R. Ryoo, and M. Jaroniec, "Adsorption and structural properties of ordered mesoporous carbons synthesized by using various carbon precursors and ordered siliceous P6mm and Ia3d mesostructures as templates," Journal of Physical Chemistry B, vol. 109, no. 49, pp. 23263-23268, 2005. 

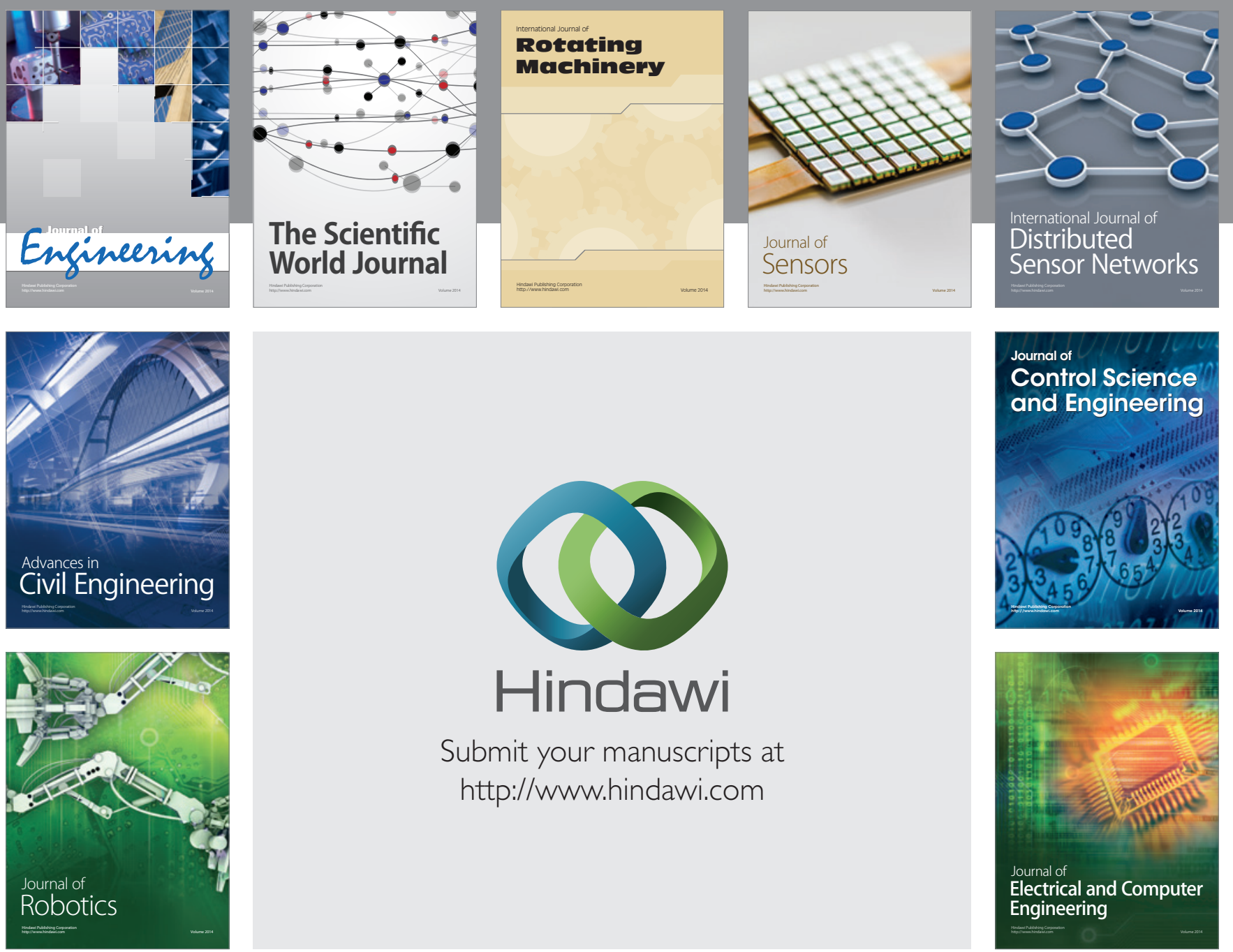

Submit your manuscripts at

http://www.hindawi.com
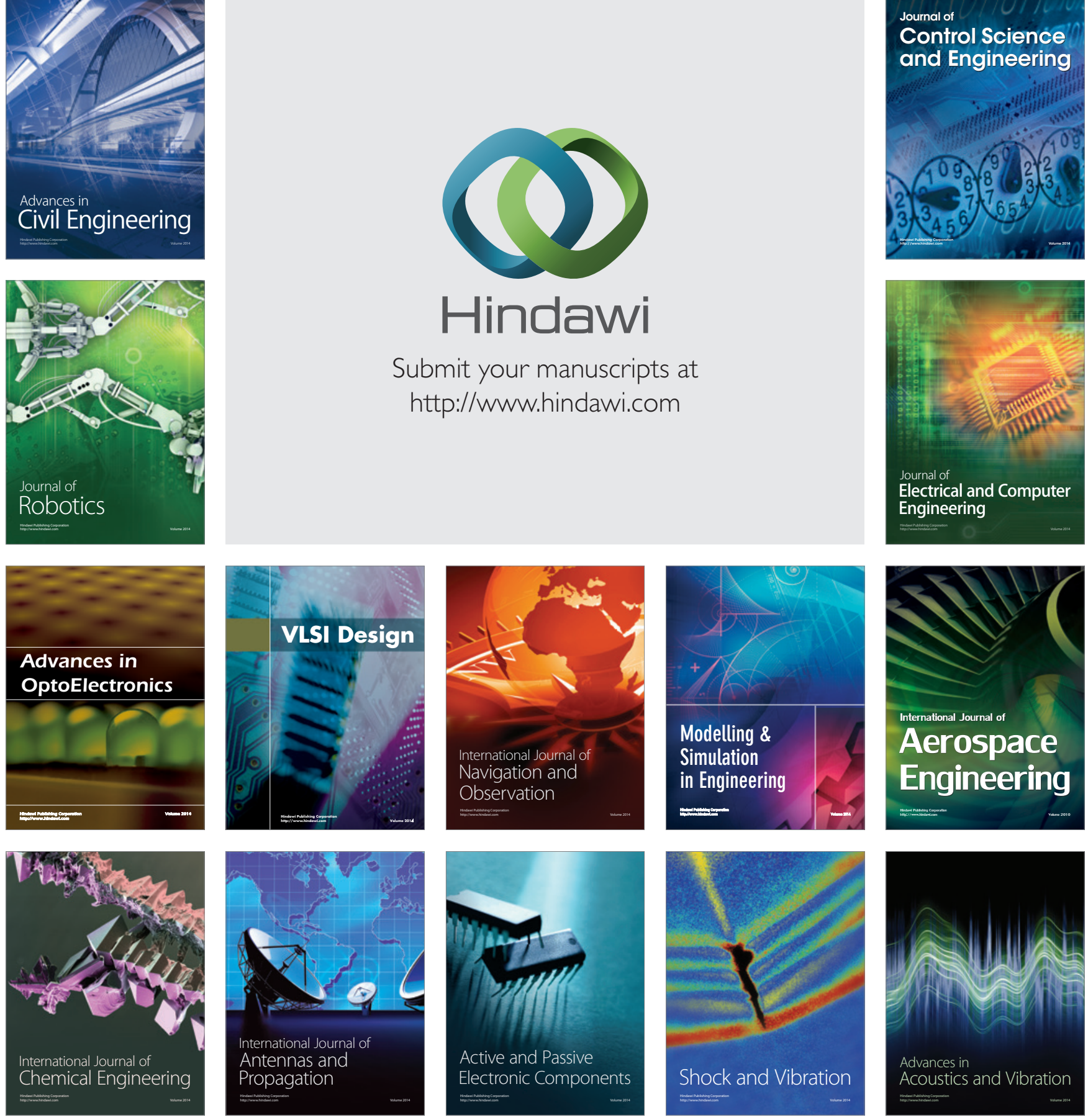